\title{
Always Learning from Each Other: Cultural Identity Development in Two Generations of Korean Immigrant Fathers
}

Using a life course framework, we compare and contrast the processes of acculturation for first- and second-generation Korean immigrant fathers in the United States. In-depth life history interviews were conducted with 20 first-generation and 15 second-generation fathers in the Midwest. With a modified grounded theory approach of constant comparison, we first explored how these fathers developed their identities in the midst of cultural and social transitions. These men's identity construction was shaped by socio-economic statuses and accessibility to cultural resources, with a marked shift over time toward integration of Korean and American identities. We then examined how these identities informed the men's socialization of their children, and the children's socialization of their parents.

Much of the literature on fatherhood has explored men's unique contribution to children's lives (e.g. Chiu \& Ho, 2006; Meunier, Bisceglia \& Jenkins, 2011). When considering fatherhood, men's unique socio-cultural and historical experiences should receive full consideration. Fatherhood is an adaptive process that is constantly shaped by socio-cultural and historical changes (Marsiglio, Roy, \& Fox, 2005;

Research Professor, Gender Research Institute, Yonsei University, Seoul, Korea (kyin92@hotmail.com)

*Associate Professor, Family Science Dept., University of Maryland, College Park, U.S.A.

Key Words: Acculturation, Asian American fathers, Cultural identity, Life course perspective
Roggman, Fitzgerald, Bradley, \& Raikes, 2002). Immigrant families, in particular, are a site for the dynamic interplay of culture, structure and agency, as fathering in these families must be understood in relation to the distinct contexts of host societies and countries of origin (Kwon\& Chuang, 2012).

Among the experiences of immigrant families, Asian American experiences provide insight into how men create their lives within and across multiple contexts. Asian immigrant men deal with two clashing sets of paternal expectations: conservative and traditional expectations from their home country and more flexible concepts from the country of destination. Nevertheless, the main focus of Asian immigrant studies has been on mothers, and reflects on women's adjustment in the U.S. (e.g. Cheah, Leung, Tahseen, Schultz, 2009). Some of these studies have even suggested that immigrant fathers could be a source of family conflict due to their loss of authority and unchanged roles (Kim, 2008; Kim, Chen, Li, Huang, \& Moon, 2009).For instance, marital relationships of Asian immigrant families are described as hierarchical, in which fathers have authority and power(Dinh \& Nguyen, 2006). Moreover, Min (1998) argued that serious intergenerational conflict could occur when younger generations follow changed expectations in the U.S. and challenged paternal authority.

Exploration of acculturation processes, including how two cultural contexts are integrated and negotiated, helps to understand how immigrant 
men's family relationships and identities develop over time. Based on current definitions of acculturation (e.g. Gibson, 1988; Kibria, 2002), we view acculturation as a process of cultural identity development of fathers themselves and their children. In addition, among diverse immigrant groups, we shed light on the processes of acculturation for Korean immigrant fathers. Koreans are one of the fastest- growing populations in the United States. According to the U.S. Census Bureau (2012), Korean population in the U.S. reached 1.7 million in 2010; this was more than a39\% increase from 1990, while the total U.S. population growth in the same period is about $14 \%$.

Until now studies on fatherhood have focused on paternal experiences for young fathers; fatherhood in later life has received relatively limited attention. Men's lives tend to be shaped in the world outside the family until mid-adulthood, and older men's roles and relationships in private worlds easily fade from attention (Thompson, 1994). This is especially true for Asian families where gender role distinction could be stronger than in western families. However, men's aging changes their family relationships, particularly the way that men think about their families and vice versa. Few studies of relationship between elderly fathers and their adult sons have emphasized that these relationships are lifelong journeys (Floyd \& Bowman, 2006; Roy, 2006). In this study, therefore, we compare and contrast acculturation of older first-generation Korean American fathers and that of younger secondgeneration fathers (hereafter referred to as G1, G2, and G3 children).

Applying a Korean American sample, we begin our discussion by exploring how these fathers develop their cultural identities. We then examine how the cultural adaptations of these two generations of fathers shape socialization of their children - and of each other. The purposes of this study are 1) to explore acculturation processes of fathers in different life stages; and 2) to understand how lives and cultural identities of fathers and their adult sons are interrelated during the midst of dynamic cultural and social transitions.

\section{LIFE COURSE PERSPECTIVE ON FATHER INVOLVEMENT}

We apply concepts from the life course perspective: "how chronological age, relationships, common life transitions, and social change shape people's lives from birth to death" (Marsiglio \& Roy, 2012, p. 170). The life course perspective integrates our examination of cultural negotiation and contextual changes. Three concepts -- lives in time and place, human agency, and linked lives -- apply in the study of Korean immigrant men in the U.S.

The life course concept of time and place is essential for exploring men's acculturation within different and often paradoxical contexts of both country of origin and destination (Chan, 1998; Jasso, 2003). As a tool kit of symbols, stories, rituals and world-views that people can use to create their lives, culture offers strategies which order actions through time (Swidler, 1986). Defined in this way, culture shapes but does not decide one's thoughts or behavior; it "settles or oversettles" people's lives by interacting with other structural or historical elements. Culture can provide continuity and consistent meanings and materials to construct human action for each group. In contrast, during periods of social transformation, cultural ideologies help to establish strategies of action in a new context. Swidler (1986) states that even during the most drastic ideological transitions people apply many unstated cultural assumptions.

Similar to cultural processes in "unsettled lives," acculturation reveals how Korean American fathers confronted two sets of cultural norms and paternal expectations. Gibson (1988) defined acculturation as an additive process in which the old traits are not lost, but blended with the new. Kibria's study of Asian immigrants (2002) defined acculturation as a process by which immigrants are integrated into the dominant society. According to her definition, the outcome of acculturation is uncertain, so immigrants must shape the terms of their own integration.

First-generation immigrants have been the main subject of studies of acculturation. The lives of G1 Asian immigrants have been more unsettled and they have had more difficulty with acculturation 
than their G2 children (Chan, 1998; Lee, Cho, Kim, \& Ngo, 2000). This is especially true for Korean immigrant fathers, who have had unique experiences among other Asian Americans. Most of these G1 immigrants were born during or right after the Japanese colonial period and experienced the Korean War during their childhood or early adolescence.

Korean families started migrating into the States in 1965, right after the abolition of the Asian Exclusion Act (Yu \& Choe, 2003). The lifting of this Act increased the number of Asian families who came to the U. S. First-generation fathers in this study are the ones who came to the U.S. around this period. Many of these men opted to emigrate from Korea as the country struggled with the creation of a Western framework of democracy and a market economy in the face of continuing poverty and deeply rooted traditional Confucian family values.

Even Korean Americans who were born in the States or immigrated before school age may have led "unsettled lives" and struggled with their ethnic identities (Min, 2002). Many G2 Asian Americans experienced a sense of "not belonging" in American culture and felt much the same marginalization that their G1 parents did (Kibria, 1999; Thai, 1999). Min and Kim (2000) also found that G2 Asian Americans often undergo prolonged acculturation processes because they have to contend both with the model minority expectations (Kibria, 2002) and with traditional expectations from their parents. Based on analyses of narratives about ethnic and racial identity development from Asian American professionals, Min and Kim (2000) concluded that G2 Asian Americans tend to develop strong bicultural identities, due to immersion in the multicultural environment of U.S. colleges and retention of strong ties to their country of origin.

Human agency consists of individuals' active development and maintenance of their identities, attitudes and behaviors (Giele \& Elder, 1998). Settersten (1999, p. 253) defined this process as "agency within structure," in which "human lives are shaped by and themselves shape social structure and both are constantly changing." The concept of human agency helps to explain why and how G1 and
G2 fathers actively construct their thoughts and behaviors as they confront socio-cultural transitions.

Although previous studies have centered on young fathers' physical interaction and caregiving with young children, Pleck and Stueve (2001) insisted that paternal involvement has "cognitive and affective schema that closely link fathers themselves and their children" (p. 219). Fathers' involvement also includes their moral engagement for next generation (Gabarino, 2000; Snarey, 1993). Understanding the symbolic or moral dimensions of paternal involvement could help us to understand how immigrant fathers create their paternal roles, for example by maintaining ethnic attachments and handing them down to the next generation (Hurh \& Kim, 1984). Applying the concept of human agency, we focus on Korean immigrant fathers' moral and symbolic efforts to socialize the next generation in terms of their cultural identity.

Lastly, the concept of linked lives indicates that changes in individuals' lives directly affect the lives of others (Giele \& Elder, 1998; Settersten, 1999). Individual lives are linked to each other in their relationships and in their life domains (e.g., work, family or education). This concept illustrates how G1 and G2 fathers create meaning about their life changes in relation to each other's life transitions. This study focuses on linked lives between G1 fathers and G2 sons. Most studies of immigrant families rely on their first or second generations to explain family conflict or problems (Foner, 1997). According to Fingerman (1995), views of family life and relationships depend on the reporter's generational status (parent or child). Among the four potential parent-child dyads, the father-son relationship is possibly the most understudied and most vulnerable (Hong \& Min, 1999; Kaufman \& Uhlenberg, 1998). Relationships between older fathers and sons in Asian immigrant families have been ignored.

In sum, we used concepts from a life course framework to explore identity construction during cultural and social transitions. We explore how Korean American fathers of different generations negotiated processes of acculturation, or integrated their sense of being Korean and/or American, over time. We asked two sets of questions: 
- How do distinct processes of acculturation shift over time for first-generation and secondgeneration Korean immigrant fathers? How are processes of identity construction for each of these two generations linked?

- How do fathers of these two generations decide to socialize their children to be Koreans or Americans? How do children socialize their fathers into new cultural identities?

\section{METHOD}

\section{Qualitative Approach}

Qualitative methods emphasize the construction of meaning, the importance of context, and dynamic processes within fathering (Roy \& Kwon, 2007). An enhanced focus on cultural values and interpersonal relationships makes these methods conducive to the study of life experiences of ethnic minorities (Mertens, 1998, Min, 2002). Fatherhood in ethnic minority families could be examined through qualitative methods, because definitions of fatherhood vary across cultures (Roggman et al., 2002).

Aging fathers and their adult sons in Asian immigrant families have rarely been examined, and for this reason, we rely on exploratory methods to develop new concepts and a new model. Our inquiry is guided by sensitizing concepts from a life course framework, but we use a modified grounded theory approach to allow for discovery of new dimensions of acculturation for Korean immigrant fathers. The purpose of grounded theory is to construct theory using inductive strategies, rather than to deductively test or generalize existing assumptions (Daly, 2007).In this study, we adopted an open and flexible attitude and concentrated on important topics raised by the fathers themselves.

By integrating these theoretical and methodological approaches, we can utilize life histories to understand lives within changing contexts over time. We therefore turned to life history narratives to provide essential information about what happened in the past, how things became the way they are now, and how past experiences are associated with present lives (Giele \& Elder, 1998; Settersten, 1999).
Settersten (1999) explained that a retrospective lifehistory interview "offers an excellent alternative to prospective longitudinal designs, especially for those interested in the entire life course, given that the gathering of life-history data requires respondents to reflect on and offer a detailed account of the past" (p. 152).

\section{Participants}

Both G1 and G2 participants were solely Korean in ethnicity, not of a mixed ethnic background. All were married, and they lived outside of Korean enclaves (e.g., Los Angeles, New York) at least until the G2s turned 18. The G1s were born and raised in Korea and moved to the States from the late 1960s to the early 1970s. These participants had at least one son who was married and the father of at least one child. G2 fathers were either born in the U.S. or immigrated before their $10^{\text {th }}$ birthday, and had at least one child.

We recruited a purposive sample of $20 \mathrm{G} 1$ and 15 G2 fathers (see Table 1). The total sample of 35 fathers included 11 G1-G2 pairs. Paired samples were recruited primarily for convenience, using a snowball technique in which men indicated whether or not their fathers or sons would be interested in participation. If they did identify their own father or son, we found that these men had comfortable and relatively positive relations. We decided to recruit unpaired fathers and sons as well to capture family relationships that might have been more tenuous. In effect, when men did not recommend their fathers and sons, we found their hesitancy might be due to more distant relations. However, in our analyses, there were many more similarities than differences in acculturation experiences between paired and unpaired samples. Thus, we did not explicitly compare the two groups.

We initially recruited participants from Korean churches, since almost $80 \%$ of Korean immigrants attend church (Chan, 1998). We then expanded recruitment to provide variation in the sampleby searching for participants in cultural institutions and an automobile insurance office in Korean Towns. When prospective participants were found, we sent them an official letter to explain the purpose and 
Table 1. Characteristics of Participants in the Study

\begin{tabular}{|c|c|c|c|c|}
\hline \multicolumn{3}{|c|}{ Characteristics } & \multirow{2}{*}{$\begin{array}{c}\mathrm{N}(\%) \\
3(15 \%)\end{array}$} & \multirow[t]{2}{*}{ Mean } \\
\hline Age (in years) & & Under 60 & & \\
\hline & \multirow{3}{*}{ G1 } & $61-70$ & $12(60 \%)$ & \multirow{3}{*}{67.6} \\
\hline & & $71-80$ & $4(20 \%)$ & \\
\hline & & Over 81 & $1(5 \%)$ & \\
\hline & \multirow{3}{*}{ G2 } & Under 30 & $2(13 \%)$ & \multirow{3}{*}{35.4} \\
\hline & & $31-40$ & $10(67 \%)$ & \\
\hline & & Over 40 & $3(20 \%)$ & \\
\hline \multirow{5}{*}{$\begin{array}{l}\text { Length of } \\
\text { Immigration } \\
\text { (in years) }\end{array}$} & & Less than 30 & $4(20 \%)$ & \multirow{5}{*}{34.6} \\
\hline & & $31-35$ & $7(35 \%)$ & \\
\hline & & $36-40$ & $7(35 \%)$ & \\
\hline & & $41-45$ & $1(5 \%)$ & \\
\hline & & More than 46 & $1(5 \%)$ & \\
\hline \multirow{9}{*}{$\begin{array}{l}\text { Age of } \\
\text { Immigration } \\
\text { (in years) }\end{array}$} & \multirow{4}{*}{ G1 } & Under 30 & $10(50 \%)$ & \multirow{4}{*}{33.7} \\
\hline & & $31-40$ & $6(30 \%)$ & \\
\hline & & $41-50$ & $3(15 \%)$ & \\
\hline & & Over 51 & $1(5 \%)$ & \\
\hline & \multirow{5}{*}{ G2 } & Born in the U.S. & $7(47 \%)$ & \multirow{5}{*}{1.9} \\
\hline & & $0-1$ & $2(13 \%)$ & \\
\hline & & $2-3$ & $3(20 \%)$ & \\
\hline & & $4-5$ & $2(13 \%)$ & \\
\hline & & Over 6 & $1(7 \%)$ & \\
\hline Number of & \multirow{4}{*}{ G1 } & 1 & $2(10 \%)$ & \multirow{4}{*}{2.6} \\
\hline \multirow[t]{5}{*}{ Children } & & 2 & $8(40 \%)$ & \\
\hline & & 3 & $6(30 \%)$ & \\
\hline & & 4 & $4(20 \%)$ & \\
\hline & \multirow{2}{*}{ G2 } & 1 & $6(40 \%)$ & \multirow{2}{*}{1.6} \\
\hline & & 2 & $9(60 \%)$ & \\
\hline \multirow[t]{7}{*}{ Occupation } & \multirow{4}{*}{ G1 (Include retirees) } & Professional (e.g. doctor, pharmacist) & $11(55 \%)$ & \\
\hline & & Small business owner (e.g. laundry, grocery) & $6(30 \%)$ & \\
\hline & & Factory workers & $2(10 \%)$ & \\
\hline & & Other & $1(5 \%)$ & \\
\hline & \multirow{3}{*}{ G2 } & Professional (e.g. doctor, lawyer, pastor) & $9(60 \%)$ & \\
\hline & & Company employees & $5(33 \%)$ & \\
\hline & & Company owner & $1(7 \%)$ & \\
\hline
\end{tabular}

procedures of the interview.

\section{Data Collection and Analyses}

To explore G1 and G2 fathers' lifelong experiences, we conducted individual interviews with the fathers.
The interviews, which took 40 to 90 minutes, were conducted either in Korean or in English. The main interview questions included "How do you identify yourself in terms of culture?" "How has your cultural identity changed over time?" "How do you 
identify your children (G2s and G3s) in terms of culture?" and "What do Korean culture and American culture mean to you?"Korean interviews were translated into English for the analysis. Trustworthiness of the data was enhanced through use of multiple coders. We also promoted triangulation through the use of multiple sources of data (supplemental interviews with wives and church members) and multiple methods of data collection (field notes, and observation) (Lincoln \& Guba, 1985).

We applied three inductive coding procedures of grounded theory (Strauss \& Corbin, 1990). In the open coding stage, data were coded with sensitizing concepts (e.g. language barriers, identity conflict) or with emergent codes (e.g., reciprocal socialization, socio-economic group difference). In this first stage, discrete phenomena that emerged from G1 and G2 interviews were labeled through close examination.

Data were then re-examined using axial coding. In this stage, we compared and contrasted patterns that appeared among individual fathers and across G1 and G2 groups by connecting categories and subcategories. For instance, with regard to withincase analysis, different types of individual acculturation patterns were compared. Regarding between-case analysis, difference and similarities of acculturation patterns observed in G1 and G2 groups and different socio-economic groups were compared.

Finally in selective coding stage, we selected core categories and related them to other categories to tell "stories" about concepts and patterns (Mertens, 1998). These stories are final results that can be shown in our findings section. As findings in this study, we identified acculturation as our core category at this stage of analysis. We linked secondary patterns and themes to this core category, first by contrasting acculturation for G1s and G2s, and then by examining socialization of one's children and parents, which reflects shifting acculturation processes over time and across generations.

\section{FINDINGS}

\section{Development of Cultural Identity Over Time}

G1 fathers Korean immigrant families' acculturation processes were initially shaped by their reasons for coming to the U.S. Among $20 \mathrm{G} 1 \mathrm{~s}$ and $4 \mathrm{G} 2 \mathrm{~s}$ who were not part of a G1-G2 pair, 12 (52\%) first came to the U.S. due to G1s' professions or postgraduate education. Most of those G1 fathers established themselves as doctors and engineers shortly after immigration or upon finishing their degree. According to those G1s, living in the U.S. was very different from others.

There are people who are working for American companies to join the mainstream society, and people who have their own little businesses. Their ways of living are very diverse. It is hard to define in one word, but I think people who are well educated and have professional occupations seem to live in same patterns as Americans (Min, architect, G1 father).

In contrast to the fathers who came to the U.S. for educational or professional reasons, G1 fathers who left Korea for the sake of their children (e.g., better education, for medical treatment) $(n=6,26 \%)$ or for economic reasons $(n=4,17 \%)$ struggled from the beginning. Hong, 73, came to the States in 1978 to send his sons to school. He said, "well, lives of immigrants are hard---When we came here, there was no plan. We were just busy making the ends meet." Most of these G1s worked in factories or opened small businesses like corner stores or laundries. Those fathers also tended to have difficulties learning English and were often under employed.

After several decades of living in the U.S., most G1s ( $\mathrm{n}=14,70 \%)$ identified themselves as "Korean Americans" and admitted their cultural identities had changed. Both unstable employment and busy training schedules delayed these men's entry into American society, and ultimately many felt that they adapted only after their livelihoods became more stable.

This eventual acculturation and G1 fathers' subsequent identity construction were associated with several contextual factors. One of the most important factors was G1s' job status. Men who had entered the professions, such as doctors or engineers, were more likely to provideG1s with opportunity of contacting with mainstream American culture than 
non-professional jobs. Han, a 62-year-old anesthetist, did not adjust right away. He said, "Maybe after I finished training... about four to five years after moving here and opened my own clinic. From then, I could have more opportunity to socialize with American people."

However, prestigious occupations did not lead to immediate acculturation. Since these fathers lived outside Korean enclaves their limited access to Korean people or communities accelerated the change in their cultural identity, regardless of socioeconomic status. Won had lived in a city with no Asian population.

We were the only Koreans and foreigners. We went to an American church because there was no Korean church. Everything was so strange. That was where we had to live...so, no choice. It was a small city and everybody knows you, your kids, and your wife. Everybody knows what happens in our house. So, I could not do anything but adjust (Won, retired, G1 father).

After 40 years of living in a small city, Won moved to a city with a larger Korean immigrant population, and experienced reverse culture shock. "We have done much cultural adaptation for about 40 years. And to go back, we have to learn another culture."

Naturalization encouraged the change in G1s' cultural identity. Chung, a 67-year-old retiree emphasized the significance of acquiring U.S. citizenship. "I got American citizenship, so I have to live as an American, for America. I swore that I will respond whenever the country needs me. I said 'I do', so I have to follow it." Naturalization provides a symbolic meaning of becoming an American.

Family members, especially G2 children, could hastenG1s' acculturation and identity changes. Children who grew up in the U.S. brought American culture into the family and encouraged their fathers to adapt to the U.S. culture. According to Hong, "when we first came here, we lived in totally Korean style. But as kids got older, they imported American culture and follow edit."

Interestingly, G1 fathers' cultural identity was shaped not only by American society, but also by social changes in Korea. These fathers found that they were no longer involved in Korean culture when they knew Korean society had changed since their departure. Jang clung to his Korean identity. Nevertheless, he felt detached from Korean culture when he disagreed with the social changes there. "When Korean statesmen are doing a bad job, and broadcasting stations, such as KBS and MBC act like communists, I sometimes feel like I am detached from that culture."

G2 fathers Throughout their childhood, most G2 fathers $(n=12 ; 80 \%)$ thought of themselves as - or at least desired to be -- " $100 \%$ American." For these men, identifying themselves as Americans was part of "being accepted" by their school friends. Andrew, a 32-year-old doctor, said "I did not want to be Korean because I was one of the few two or three Asians in our school. I was the only kind of person who looked like me...back then, I got teased."As Andrew stated, G2s' attitudes toward their cultural identity was first associated with the social context of the time. Simon, in contrast, claimed that he wanted to be American because he had known so little about Korean culture when he was young.

When I was younger almost everyone wanted to be American; no one wanted to be Korean. The only thing that was Korean was that we went to a Korean church. We didn't have anything like Korean school. My son goes to Korean school here run by our church, but I don't recall having anything like that when I was younger (Simon, attorney, G2 father).

Discomfort or disagreement with Korean culture was cited as another reason that the G2 fathers distanced themselves from their Korean identity when they were growing up. According to Luke, he "liked to avoid Korean culture. I thought my future was away from it. I was very offended by Koreans [G1s] in my church many times."

A smaller group of men $(n=3 ; 20 \%)$ embraced a Korean identity as children, and had worked to maintain this identity. The fathers described cultural pride as the main reason for maintaining their Koreaness. Philip, a 34-year-old G2 father, stated, "My personality was different from others. I really always appreciated being who I was. I'm very proud. I'm a proud person. I'm Korean and I'm proud." 
However, many fathers moved beyond childhood and adolescent resistance and crafted a more explicit Korean identity as adults. Andrew admitted, "I think I have a little more respect than when I was a kid because I understand a little more, I guess. Just give more appreciation that that is where I am from and that is my identity." As a consequence, most G2 fathers $(n=12,73 \%)$ moved into an acceptance of a Korean American identity as a part of their adulthood. A turning point was often in high school or college, when the fathers had more opportunity to meet people from other cultures, including people from Korea. Luke, for instance, started building his cultural identity as a second-generation when he went to college.

When I was in high school, my ideas started softening a little bit. But when I went to college, I had many chances to experience different cultures. -- That time I realized there were a lot of cultures and I had enjoyed that. I did not necessarily want to be 100\% American (Luke, doctor, G2 father).

For some, marriage to a woman who came to the U.S. as an adolescent or as an adult was a turning point. Thomas, a 33-year-old franchising manager, reported that "My wife was "a Yoo-Hak-Saeng [international student]. She was more Korean than American. So once I got married, I experienced more of being Korean. She introduced me to more stuff than I ever knew.'The fathers tended to accept and learn Korean culture with little resistance from their wives.

Finally, some G2 fathers described visiting Korea as a turning point in their Korean identity. Simon's trip to Korea made him curious about Korean culture.

I went to Korea to visit my uncle and that was the first time I went back. That was probably 1989, 17 years later. And when I went back there, it was just very different, and I wanted to learn more about the Korean tradition and things like that (Simon, attorney, G2 father).

In effect, these young men believed that they would encounter a very traditional notion of Korean identity during their visit. However, they found something quite different: contemporary Korean men were not as traditional as they had been led to believe by their immigrant fathers, who had often overemphasized the traditional aspects of Korean culture in their daily lives.

In sum, distinct processes of acculturation emerged for both G1 and G2 Korean immigrant fathers. Both groups of fathers negotiated identity from a sense of agency within socially structured opportunities to be Korean, to be American, or to be Korean American. However, narratives of acculturation varied across the groups. G1 fathers emphasized how their acculturation resulted due to adaptation to environment, including employment, cultural isolation, citizenship status, and influence of their children. In contrast, G2 fathers emphasized acculturation as a personal choice related to movement from childhood to adulthood. However, their identities also were intimately shaped by the structural opportunities preferred by their parents, including choice of schools, church, and marital arrangements.

\section{Cultural Socialization of Children}

G1s socializing G2s Although G1 fathers were the primary source of G2 sons' cultural values, it did not mean that G1s deliberately tried to instill their own cultural values intheir sons. Jang stated, "I will just keep Korean culture and let my kids live in their own ways." Many G1 fathers considered what would be the most practical for their children's lives to made decisions on how to socialize them. Several G1s indicated that they had decided to socialize their sons as Americans since they would have to live in the U.S. For Yoo, the decision to socialize his sons as Americans was made when they became preschoolers and started interacting with their American peers. He stopped emphasizing Korean values after seeing his oldest son's struggles between the two cultures.

We first thought Korean values were important. That's why we gave our first son a Korean name. But when Matthew was born, we thought it was not necessary. It was not convenient for them. When he interacts with other people or his friends, they would call his English name. Our perspective changed to think what is the most convenient for the children (Yoo, retired, G1 father).

Luke, a G2 father, said that his parents "decided 
when I was very young that they would help me to get used to this culture because this is where I was going to live. They wanted me to be successful in America, not being hindered by Koreanness." At the same time, he insisted that his parents' decision to socialize their children as Americans was a "real struggle" for them since G1s were not used to American culture and had limited English language ability.

In contrast to the fathers above, some G1 fathers-especially those with non-professional occupations-attempted to provide their G2s with a sense of culture by teaching Korean language or values at home. Cho was strict about using Korean language at home although it cost him the opportunity to improve his proficiency in English.

If we used English at home, we might speak English pretty well by now. But we gave up, because we had to teach them a little bit of Korean. Thus, when they came home, they had to speak Korean. They can speak English when they were not at home. But when they were with mom and dad, they had to speak Korean (Cho, laundry owner, G1 father).

Choi, a G1 father, similarly emphasized Korean values when his son was young. "When [my children] were growing up, I told them to remember they were Koreans even though they were born in the States."

A few G1s taught their children about Korea not to socialize them as Koreans but for practical reasons. Won taught his children about Korea so that they could adjust to American life without feeling embarrassed or ashamed. Nevertheless, he stopped when he saw that his children were doing well in school and had made friends.

We taught him some songs like the national anthem. I think he still remembers that. In our back garden, we had a flower bed in the shape of a Korean map, and we even made Baik-Doo Mountain with flowers. We were the only Koreans in that small city, so I felt you have to give them some pride as Koreans. (Won, retired, G1 father).

Whether for practical or emotional reasons, the G1s' efforts to teach their children Korean values and language were resented by young G2 boys. However, these G2s dropped their resistance when they realized the practical value of Korean cultural learning. Thomas appreciated his parents' effort to instill a sense of Korean culture in him because it improved his knowledge of languages and martial arts.

I am glad that they made me to do those things because first of all, some of the knowledge and skills I got. I use them now. About Tae-kwon-do, as a kid, I didn't like that. But I am grateful for that now. That's why I send my kids to Korean school so that they don't forget their Korean heritage. (Thomas, franchising manager, G2 father).

In contrast, Philip regretted having lost his chance to learn Korean, which would have been very useful for his business. He explained, "Back then, you say to yourself that I'm never going to use that language. But now, I wish I would have studied it more, because in my profession, lots of my clients are Koreans."

Mothers' perceptions about G2's (or G3's) cultural socialization was beyond the scope of this study. However, some G2s reported G1 mothers' role on connecting G1 fathers and G2 children. For Mark and Luke, their mothers helped them to appreciate their fathers' involvement in their lives. Mark said, "I understood what he [G1 father]was doing, and my mother kind of explained it to me."

Luke was more explicit:

My father never said anything. But when I talked to my mother about my father when I was in college or later in life, she told me that he had opinions---As I hear from my mother, my father was actively involved and had a lot of opinions and thought about my life (Luke, doctor, G2 father)

Thus, there might be some possibility that G1 mothers indirectly shaped G2s' socialization by telling G1s what to do and by informing G2 children about fathers' thoughts and opinions.

G2s socializing G3s All the G2 fathers in the sample defined their third-generation children to be even more Americanized than themselves, and felt no need to Americanize G3s. Josiah said that his children could not avoid being Americanized: "You cannot avoid American culture unless you already have sub-culture. But we don't have that sub-culture. 
We don't have to socialize them to be Americans." G2 fathers, whose lives in the States were more settled than their fathers' and were more accustomed to American culture, wanted to tell G3s about their ethnic heritage. Isaac wished to raise his newborn son to balance American and Korean cultures, so that he would not lose a sense of his ethnic background.

I think he will probably consider himself as more American. But I don't want him to forget his heritage of being Korean. His mother is a real "Korean" woman, and I am more "American person." So there should be a balance. We decided to raise him both with English and Korean (Isaac, operational manager, G2 father).

Isaac's decision to raise his son in both the American and Korean cultures partly derives from the fact that his wife was a first-generation Korean American. Chris, who married a European American woman, believed that "cultural identity might be more important to my daughter in the future, growing up in a bicultural environment." $\mathrm{He}$ thought that teaching the "good values" in Korean culture would be important for his interracial daughter.

In the future, I think it'll be good for my daughter to know some of her cultural identity...maybe a part of it is that what I felt about the Korean culture. There are a lot of good parts of things, which I would attribute to Korean culture respect, being a dutiful son (Chris, doctor, G2 father).

Similar to what G1s reported, teaching Korean language and Tae-kwon-do was an essential way for G2s to teach G3s their Korean heritage. Since G3s had more access to Korean resources than their G2 fathers did, the G2s often sent their children to Korean language schools or other institutions. For instance, Mark felt good about giving his children the opportunity to learn Korean, which he had not been able to do when he was young.

I hope my kids to have more exposure to Korean culture or language. My wife said that she wants to start sending my son to Korean language school. I said, 'Fine let's do it'. If they actually could learn more than I did, that would be great (Mark, business owner, G2 father).

The fathers, especially those who were married to G1 women, tried to use Korean at home. Joseph wanted to use Korean as the main language at home since he was afraid of that his children would forget their Korean heritage.

They go to Korean schools on Saturdays. They learn to read and write. I try to make our primary language Korean at home. But as kids get older, it gets more and more difficult. I fear that if I don't persist in making them speak Korean, the values of who they are will be totally lost. I didn't know what Korean was, and I kind of found it after I got married (Joseph, marketing manager, G2 father).

Since he had limited Korean language skills, Luke planned to learn more Korean so that he could speak Korean with his daughter. "We try to teach her that she is Korean and speak to her in Korean, though my Korean is very limited. I can speak like a four year old. So hopefully I can learn a little bit too."

However, a few G2s believed they should not put as much pressure on their children as their G1 fathers had put on them. As a consequence, they objected to imposing lessons in Korean heritage on their children. Matthew, who considered his father and himself as very Americanized, had little intention of socializing his children with Korean culture. He did not want to bother them by giving them more burdens other than school work. He explained,

We will not send our kids to Han-Gul-Hack-Kyo [Korean language school], and it is not because we don't want to learn Korean culture. I am not going to send my kids to another school for 4 to 6 hours on Saturday morning. I just don't think that is, honestly, on and off the record, I just think that's psycho. [laugh] (Matthew, youth pastor, G2 father).

The G2s also reported that their children's attitudes toward Korean heritage were different from the attitudes that they had had when they were young. With increasing diversity in the U.S., G3s took more pride in their uniqueness and wanted to explore their ethnic background. John explained his interracial son's curiosity about his Korean background. 'If you ask him 'what are you?' he will answer 'more Korean than Swedish or German.' -- 
For the most part, his Korean heritage is something that is kind of unique. I think he's proud of it."

Reciprocal socialization across three generations Socialization to Korean culture was a complex process, however, and did not flow linearly from older to younger generations. Children returned the favor and socialized their fathers to new meanings of being Korean. G2 fathers gained enhanced skills through encouraging their children to learn more about Korean heritage. As Luke asserted, his attempts to teach Korean language, to celebrate Korean holidays, and to expose his children to Korean artistic expressions also taught him about nuances of a Korean culture that was dynamic, contemporary, even global in reach. These men were also ushered into closer relations with their own fathers through the emerging closeness between grandfathers and grandchildren. Josiah explained that his children experienced Korean culture firsthand and grew more curious about the culture when they visited their grandparents.

My children call me Ah-Bba [Daddy] and speak Korean with my parents. They call my parents HalAh-Buh-Ji [Grandpa] and Hal-Muh-Ni [Grandma]. My kids have Korean middle name, which my parents only use (Josiah, doctor, G2 father).

If G2 fathers barely spoke Korean or knew Korean culture, G1 grandparents became cultural resources not only for G3 children, but for G2 adults, who developed an adult interest in their culture alongside their children's first attempts at identity construction.

True to the definition of linked lives, a transition in one generation's identities rippled into transitions for another generation's identities. For G1 men, becoming grandfathers invited new understandings of being Korean or American. Their interaction with grandchildren took on a different character from their earlier interaction with their own children. G1 grandfathers relinquished many of the traditional role expectations of Korean fatherhood, expressing themselves more freely, and playing with grandchildren. In these new roles, G1 men perceived that they had been socialized into a new type of "American" grandfather by their sons, with expectations for more interaction, more emotional attachment.

However, from their G2 sons' perspective, the G1 grandfathers were not "American" grandfathers. By the nature of their complex relationship with retaining a traditional but outdated Korean identity from the time of their immigration to the States in the 1970s, G1 immigrant fathers were more "Korean" than men who lived and parented in Korea itself. Instead, G2 fathers noted that G1's interactions with G3 children were similar to new enhanced role expectations for grandfathers, and an encouragement of emotional attachment, that was now common among contemporary grandfathers in Korea, in the United States, and in many developed countries.

\section{DISCUSSION}

Studies of intergenerational relations in Korean immigrant families have focused on G2s' identity changes and their clashes with G1s who remained committed to their traditional Korean identity (Kim, 2008). Drawing from the concept of "time and place," "human agency", and "linked lives" in a life course framework, we find that many G1s and G2s have undergone acculturation and modified their cultural identities. The retrospective life history interviews allowed us to focus on intra-individual change over time.

First, the concept of time and place can be well applied when understanding identity development processes of G1 and G2 fathers. We could explore that particular social and historical situation of America and Korea at the time of their immigration and growth were closely related to their cultural identity development. For G1 fathers, development of an Americanized identity was critical for adjustment and survival in the States. During the time oftheir immigration to the United States, there were few ethnic resources in local communities. In contrast, for G2s, the expansion of Korean communities after the 1980s and the increasing number of opportunities to interact with Korean culture encouraged them to think more about their Korean identity. Access to Korean resources also 
encouraged G2 fathers to socialize their children about Korean culture and identity.

It is also important to emphasize how social changes in Korea as well as in the U.S. shaped G1 and G2 men's cultural identities. This finding in part supports the cultural discussion that people rely on existing cultural norms to adjust to new cultural contexts (Jasso, 2003; Swidler, 1986). Nevertheless, limited attention has been paid to how contexts from previous countries actually shape the acculturation of immigrants. In this study, we found that cultural and social contexts in Korea not only shaped people's identities and roles at the time of transition, but they had ongoing impact on the development of G1s' and G2s' cultural identities throughout the life course. Furthermore, in addition to the values and norms that people had experienced before immigration, ongoing changes in the country of origin were closely related to their cultural identity development.

The concept of linked lives in a life course framework also provides a new perspective to understand complex dynamics between G1 and G2s' identity construction. For Korean immigrant families in this study, acculturation and changes in cultural identity rippled into other family members' identity and role changes. When G2s became more Americanized, they brought American values home and encouraged their G1 parents' cultural identity and role changes. In contrast to previous studies that articulated G1 fathers' stable cultural identity and the gap between generations (Min, 2002), G1 fathers in this study began to accept a more Americanized way of life and expectations when they saw the changes in their sons' identities. Moreover, a view onto reciprocal socialization showed that G2s' decision about offering their children a sense of their ethnic background shaped G1 fathers' roles as a cultural educator. These findings complicate prior assumptions that family conflicts were based on G1 fathers' sense of being Korean. If we consider acculturation as a process that unfolds over the life course, negotiation of G1s' Korean identity could play an important role in family conflict as well as family integration.

Fathers' decision making about endowing succeeding generation's cultural identity is closely related to the concept of human agency. Both G1 and G2 fathers decide to construct their children's cultural identity in a certain way based on their experiences in the U.S. In other words, in many families, fathers of both generations assigned cultural identities to their children that they themselves did not have. This tendency could be understood in relation to the fathers' expectations of their children. Asian American parents stress academic and professional achievement in order to ensure their children's success in a new country (Kibria, 2002), and the study findings expand those claims. Parental expectations of their sons to pursue a more successful life in the States not only include doing well academically and professionally, but are also indicative of developing an American identity and being different from their fathers.

One of the key findings in this study is the amount of variation within each generation. Social and historical circumstances shaped each G1 father's experiences differently, depending on his reasons for immigrating and his occupation upon arrival in the U.S. These findings about within-group differences complicate previous findings that generalized all Korean immigrant families. Most studies about Asian Americans considered families settled in large cultural communities, and insisted that fathers were underemployed and had financial hardships after migration and therefore could not easily adjust to the society (Chan, 1998; Kim \& Kim, 1998). According to this study, this was the case only for the fathers who came to the U.S. for their children's education or in search of economic stability. G1 men who experienced occupational decline had more difficulties adapting to the U.S. culture and society. In contrast, dealing with a new culture with few Korean resources might not have been as much of a challenge for the fathers who kept their professional occupations and met mainstream Americans on a daily basis.

Although this study sheds light on immigrant men's life changes over the life course, some limitations must be discussed. First, although the aim of qualitative inquiry is not on generalization of results, it might be important to recollect the fact that our qualitative study included a small sample, limiting the generalizability of our results. Second, 
despite our efforts to find paired G1-G2 samples, only 11 pairs were recruited. As stated, including unpaired sample offered an advantage of recruiting men whose relationships with their fathers and sons are not necessarily positive. Few differences ultimately emerged between the two samples. In future, however, diverse strategies of finding father-son pairs could be developed to more systematically look for a range of relationship quality. For instance, asking G1 mothers to introduce their husbands and sons might be one ways of sampling G1-G2 pairs.

Lastly, inclusion of fathers from different socioeconomic classes might also give a better understanding of men's diverse acculturation process. Although most Korean immigrants are Christians and are concentrated in a relatively small number of occupations, this sample was still homogeneous in family formation and economic status. All of the G1s and G2s except for two were in their first marriage. In addition, all of the fathers had incomes that placed them in the middle or upper middle class.

In sum, this study provides insight into a number of issues in research on Asian American immigrant families. Most studies and programs that address acculturation issues for Asian American immigrant families are aimed at school-age youth, in part due to cultural biases in traditional career trajectories and the "model minority myth" (Shea, Ma, \& Yeh, 2007). However, this study suggests that acculturation is not an issue only in adolescence, but throughout the life course. In particular, we find that acculturation is an ongoing process that is relevant even to the lives of older adults, who adapt to new role expectations as caregivers of subsequent generations - and who even embrace cultural norms that had proven problematic in earlier life stages.

The study also provides insight into the emerging complexity in family relationships over time, as multiple generations cope with the expectations and realities of mobility and shifting contexts due to immigration. Relationships between G1 and G2 immigrants, in particular the relationship between Asian American G1s and G2s, are still understood as conflicting and distinct (Foner, 1997). In this study, we show that the acculturation process of G1 fathers and their feelings toward their sons are not only determined by their conservative attitudes but are also closely related to job status, English abilities, and knowledge of the new culture. Moreover, men who in prior studies were stereotyped as clinging to rigid ethnic identities were shown in this study to grow flexible and adaptable with time. In effect, the lives of Asian American immigrant men are dynamic, which is best captured in life history research (with retrospective, if not prospective, data).

Perhaps most significantly, a life course approach indicates how deeply acculturation in immigrant families is an intergenerational process. This study offers an intersectional perspective (Dill \& Zambrana, 2009) that acknowledges the complicated relationship of ethnicity, immigrant status, gender and power that could prove quite effective in our understanding of how families change over time.

\section{REFERENCES}

Chan, S. (1998). Families with Asian roots. In E. W. Lync \& M. J. Hanson (Eds.), Developing cross-cultural competence (pp. 251-344). Baltimore, MD: The Maple Press.

Cheah, C. S., Leung, C. Y., Tahseen, M., \& Schultz, D. (2009). Authoritative parenting among immigrant Chinese mothers of preschoolers. Journal of Family Psychology, 23, 311-320.

Chiu L., \& Ho (2006). Families' relations and mental health of unemployed middle-aged Chinese men. Journal of Marriage and the Family, 62, 922-936.

Daly, K. (2007). Qualitative methods for family studies and human development. Thousand Oaks, CA: Sage.

Dill, B. T., \& Zambrana, R. (2009). Emerging intersections: Race, class, and gender in theory, policy, E practice. Piscataway, NJ: Rutgers University Press.

Dinh, K. T., \& Nguyen, H. H. (2006). The effects of acculturative variables on Asian American parentchild relationships. Journal of Social and Personal Relationships, 23, 407-426.

Fingerman, K. L (1995). Aging mothers' and their adult daughters' perceptions of conflict behaviors. Psychology and Aging, 10, 639-650. 
Floyd, K. W., \& Bowman, J. M. (2006). Closeness and affection in father-son relationships. In V. H. Bedford, \& B. F. Turner (Eds.), Men in relationships: Life course and life span perspective(pp. 147-166). New York, NY: Springer

Foner, N. (1997). The immigrant Family: Cultural legacies and cultural changes. International Migration Review, 31, 961- 974

Garbarino, J. (2000). The soul of fatherhood. Marriage and Family Review, 29, 11-21.

Gibson, M. (1988). Accommodation without assimilation: Sikh immigrants in an American high school. Ithaca, NY: Cornell University Press.

Giele, J., \& Elder, G. H. (1998). Life course research: Development of a field. In J. Giele \& G. H. Elder (Eds.), Method of life course research: Qualitative and quantitative approaches (pp. 5- 27). Thousand Oaks, CA: Sage.

Hong, J., \& Min, P. (1999). Ethnic attachment among second-generation Korean adolescents. Amerasia Journal, 25, 165-178

Hurh, W., \& Kim, K. (1984). Korean immigrants in America: A structural analysis of ethnic confinement and adhesive adaptation. London, ON: Fairleigh Dickinson University Press

Jasso, G. (2003). Migration, human development, and the life course. In J. T. Morimer, \& M. J. Shanahan, Handbook of life course, (pp. 331-364). New York, NY: Kluwer Academic/Plenum Publishers.

Kaufman, G., \& Uhlenberg, P. (1998). Effects of life course transitions on the quality of relationships between adult children and their parents. Journal of Marriage and the Family, 60, 924-938.

Kibria, N. (1999). The construction of 'Asian American'. Ethnic and Racial Studies, 20, 523-544.

Kibria, N. (2002). Becoming Asian American: Second-generation Chinese and Korean American identities. Baltimore, MD: The Johns Hopkins University Press.

Kim, E. (2008). Korean immigrant fathering: Dealing with two cultures. In S. S. Chuang \& R. P. Moreno (Eds.), On new shores: Understanding immigrant fathers in North America (pp. 175-195). Lanham, MD: Lexington Books.
Kim, C., \& Kim, S. (1998). Family and work roles of Korean immigrants in the United States. In H. I. McCubbin, E. A. Thompson, A. I. Thompson, and J. E. Fromer (Eds.), Resiliency in Native American and immigrant families (pp. 225-274). Thousand Oaks, CA: Sage.

Kwon, Y. \& Chuang S. S. (2012). Korean Fathers on Canadian Shores. In S. Noh, A. Kim, and M. Noh (Eds.), Korean immigrants in Canada. Toronto: University of Toronto Press.

Lee, R. M., Choe, J., Kim, G., \& Ngo, V. (2000). Construction of the Asian American Family Conflicts Scale. Journal of Counseling Psychology, 47, 211-222.

Lincoln, Y., \& Guba, E. (1985). Naturalistic inquiry. Thousand Oaks, CA: Sage.

Marsiglio, W., \& Roy, K. (2012). Nurturing dads: Social initiatives for contemporary fatherhood. New York, NY: Russell Sage Foundation.

Marsiglio, W., Roy, K., \& Fox, G. L. (2005). Situated fathering: A focus on physical and social spaces.Boulder, CO: Rowman \& Littlefield.

Mertens, D. M. (1998). Research methods in education and psychology: Integrating diversity with quantitative and qualitative approaches (pp. 159-190). Thousand Oaks, CA: Sage.

Meunier, J. C., Bisceglia, R., \& Jenkins, J. M. (2011, November). Differential parenting and children's behavioral problems: Curvilinear associations and mother-father combined effects. Developmental Psychology, 28, pp. 1-16.

Min, P. (1998). Traditions and changes: Korean immigrant families in New York. Needham Heights, MA: Allyn and Bacon

Min, P. (2002). Introduction. In P. Min (Eds.), Second generation: Ethnic identity among Asian Americans (pp. 1-17). Lanham, MD: AltaMira Press.

Min, P., and Kim, R. (2000). Formation of ethnic and racial identities: Narratives by young Asian-American professionals. Ethnic and Racial Studies, 23, 735760.

Pleck, J. H., \& Stueve, J. L. (2001). Time and paternal involvement. In K. J. Daly (Ed.), Contemporary perspectives in family research: Minding the time in fam- 
ily experience (pp. 205-226). Amsterdam, NY: Elsevier Science

Roggman, L., Fitzgerald, H. E., Bradley, R. R., \& Raikes, H. (2002). Methodological measurement, and design issues in studying fathers: An interdisciplinary perspective. In C. S. Tamis-LeMonda, \& N. Cabrera (Eds.), Handbook of father involvement (pp. 1-30). Hillsdale, NJ: Lawrence Erlbaum Associates.

Roy, K. M. (2006). Father stories: A life course examination of paternal identity among low-income African American men. Journal of Family Issues, 27, 31-54

Roy, K., \& Kwon, Y. I. (2007). Qualitative insights and methodological challenges: Next steps in research on low-income fathering. Applied Developmental Science, 11, 234-238.

Settersten, R. A. (1999). Lives in time and place. Amityville, NY: Baywood Publishing Co.

Shea, M., Ma, P., \& Yeh, C. (2007). Development of a culturally-specific career exploration group for urban Chinese immigrant youth. Career Development Quarterly, 56, 62-73.

Snarey, J. (1993). How fathers care for the next generation: A four-decade study (pp. 55-83).Boston, MA:
Harvard University Press.

Strauss, A., \& Corbin, J. (1990). Basics of qualitative research: Techniques and procedures for developing grounded theory ( $1^{\text {st }}$ ed.). Thousand Oaks, CA: Sage.

Swidler, A. (1986). Culture in action: Symbols and strategies. American Sociological Review, 51, 273-286.

Thai, H. C. (1999). 'Splitting things in half is so white!': Conceptions of family life and friendship, and the formation of ethnic identity among second-generation Vietnamese Americans. Amerasia Journal, 25, 53-88.

Thompson, E. H. (1994). Older men as invisible men in contemporary society. In E. H. Thompson (Ed.), Older men's lives, (pp. 1-21). Thousand Oaks, CA: Sage.

U.S. Bureau of the Census (2010). Race Reporting for the Asian Population by Selected Categories: 2010. Washington, DC: Bureau of Statistics.

Yu, E. Y., \& Choe, P. (2003). Korean population in the United States as reflected in the Year 2000U. S. Census. Amerasia Journal, 29, 2-21.

Received March 8, 2012

Revised May 8, 2012

Accepted May 22, 2012 